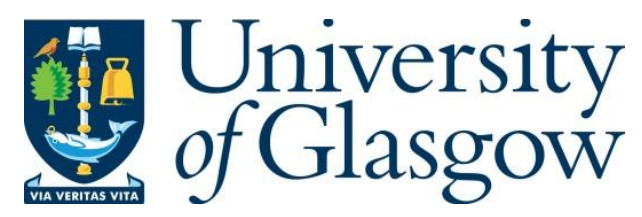

Adams, D. and Tolson, S. (2019) Valuation in the dark: Constructing perceptions of normality in failing markets. Town Planning Review, 90(4), pp. 383-406.

There may be differences between this version and the published version. You are advised to consult the publisher's version if you wish to cite from it.

http://eprints.gla.ac.uk/185780/

Deposited on: 10 July 2019

Enlighten - Research publications by members of the University of Glasgow http://eprints.gla.ac.uk 


\title{
VALUATION IN THE DARK: CONSTRUCTING PERCEPTIONS OF NORMALITY IN FAILING MARKETS
}

Paper accepted for publication in Town Planning Review

\author{
Professor David Adams \\ Urban Studies, School of Social and Political Sciences, \\ University of Glasgow \\ 25 Bute Gardens, Glasgow G12 8RS \\ E-mail: david.adams@glasgow.ac.uk
}

\section{Steven Tolson}

Independent Real Estate Consultant

E-mail: stolson@btinternet.com

\begin{abstract}
This paper explores the challenging task of assigning value to land in 'thin' or 'fragile' property markets characterised by economic restructuring and capital flight. Such markets are frequently epitomised by low demand and substantial uncertainty. The paper draws on detailed interview evidence with professional valuers to reveal the difficulties they experience in seeking to apply traditional valuation methods in one such failing market. Reliance on their own experience and professional judgement reinforces the role of valuers as market-makers with the desire to uphold perceptions of normality by placing a value of land that theoretically might appear to have none.
\end{abstract}

\section{Keywords}

Chartered surveyors; Compulsory sale orders; Thin urban land markets; Vacant and derelict land; Valuation methods

\section{INTRODUCTION}

Markets are seen in institutional theory as social constructs, reflective of the prevailing power and social relations that characterise particular places at particular times. Their performance is driven by how specific networks of market actors, which may include "brokers, market analysts, attorneys, lenders, building managers, investors, title companies, architects, and designers, builders and general contractors, engineers, environmental analysts, appraisers, planners, and surveyors" (Weber 2016: 594) apply, interpret, challenge and potentially transform market institutions. These are the 'rules of the game', which, according to Jepperson (1991), can be usefully divided between what he calls 'regimes' and 'cultures'. The first of these, regimes, refers to explicitly-codified rules and sanctions that are enforced by a central authority. But the second, cultures - as evident in the informal norms, customs, and conventions acknowledged by market actors - can be just as important in explaining market performance.

Understanding how actors mediate these different carriers of institutionalism has become an important theme of research into how land and property markets operate as social constructs. For example, in her work on Chicago, Weber (2016) argues that property development cycles 
can be explained as much by the performance of market actors as by some formulaic economic rhythm. This happens as actors deploy standardised meanings or 'market devices' (such as 'highest and best use' or 'obsolescence'), operate collectively and in concert, and generate statistical predictions that may unduly bolster confidence in the future.

In a different context, Henneberry and Roberts (2008) explore how the commonly-used and self-referential practice of portfolio benchmarking determined the investment strategies of UK property fund managers, leading to convergent fund structures that produced sub-optimal returns and generated barriers to geographical diversification. Crucially, they argue that benchmarking is not simply pursued within the market, but in practice makes the market. Similarly, Smith et al. (2006) identified the critical role of market intermediaries (solicitors, estate agents, surveyors and developers) in scripting the performance of the Edinburgh housing market during the upturn of the late 1990s, even to the extent of exacerbating the boom and creating potential destabilisation. As these sources suggest, knowing how market actors acknowledge, interpret and deploy particular regimes and cultures provides an essential entry point to understanding how specific local markets are socially constructed.

According to Adams and Tiesdell (2010), seeing markets in this way has three crucial implications for planners. First, it is important that planners recognise that "Markets are social constructs; they are not 'natural phenomena' " (Oxley, 2004: 59), since they are deeply conditioned by humanly devised rules, norms and regulations, and reflect dominant powers and interests. Second, as market structures are underpinned by State protection and regulation, planners are often as equally well placed to script market performance as other market actors and intermediaries. Third, "These insights into market construction produce a strongly disaggregated view of market structures, with each sub- or local market reflective of its own routines, procedures, distinctive relations, social culture, and other institutions ... There is thus no single land and property market, but many markets, each reflecting the different ways in which development cultures play out in different localities” (Adams and Tiesdell, 2010: 194).

Up to now, there has been relatively little research into how such insights on market construction and performance apply where economic activity is scarce rather than plentiful. In seeking to fill this gap, we draw in new empirical evidence to investigate how market intermediaries struggle to uphold perceived normality when obliged to stretch their usual set of rules, norms and conventions almost to breaking point. The specific focus of the paper is on the challenging task of assigning some kind of value to urban land within what Healey (1991) has described as 'thin' or 'fragile' property markets characterised by economic restructuring and capital flight. Such markets often also contain pockets of low-value residential property which once housed those who worked in the industrial operations.

Significantly, the paper argues that this task involves calculative practices (see Miller, 1994 and 2001) that are not just highly problematic per se but which may also serve to delay or deter the prospects of regeneration. Here, we concentrate on the modus operandi of professionallyqualified valuers in grappling with what they themselves will often describe as market failure. Through detailed empirical work conducted in one particular fragile market, the paper presents a rare insight into how individual valuers attempt to put a value on land in places where there may be little or no private development demand. It thus provides one of the few studies of its kind to explore how valuers as potential 'market-makers' actually go about their work within an urban regeneration context. The paper also tests the reaction of those interviewed to what might soon be a radical policy intervention deliberately intended to reconstruct such markets and make them work more effectively. Rather than rely on traditional valuation methods to 
assess how much such land is worth, this proposal involves the introduction of powers enabling municipalities to require that urban vacant and derelict land be offered for sale by public auction without any reserve price.

The next section explores what is already known about valuation practices in thin markets and especially within urban regeneration areas. Although there is now a very significant literature on valuation in general, remarkably few papers have specifically investigated how valuers work within a regeneration context. The section therefore seeks to connect relevant aspects of the general literature to the focus on valuation in regeneration areas provided by more specialist research. It concludes by highlighting key areas for enquiry subsequently picked up in the empirical work. Section 3 introduces the study area of North Glasgow and outlines the research method. Section 4 presents the detailed results of our eleven interviews with professionallyqualified valuers who have experience of working in the study area. The story they tell is that of a failing market with little demand, where they struggle to apply traditional methods and in which they see public-sector intervention as essential to reconstructing the market and resolving market failure. The implications of these findings, and the overall research conclusions, are set out in the final section.

\section{VALUATION IN URBAN REGENERATION AREAS}

\section{Thin real estate markets}

The concept of thin markets in the real estate literature has focused on scarcity of demand (and thus of transaction evidence) created at particular points in time by economic cycles, rather than that evident in particular places over time due to structural economic decline. Nevertheless, this broader literature offers important clues on how to interpret the operation of real estate markets in low demand areas. Crosby et al. (2009), for example, consider whether sales that do take place in economic downturns with very low trading activity should be regarded as 'forced sales' not representative of market value. Significantly, they place emphasis on whether the property has been marketed for an appropriate period, rather than on the number of potential buyers per se, concluding that "If a vendor has to sell a property for any reason, the price realised in the market could be assumed to represent market price if the property is afforded a normal marketing period and process" (Crosby et al., 2009: 11, emphasis in original).

From an American perspective, Fisher et al (2003) compare liquidity in the securities markets with that in real estate markets. With securities, constant liquidity is achieved through rapid and relentless price adjustments, making immediate sale always possible even if a lower price must be accepted. In securities markets, price and expected time on the market are therefore conflated into a single dimension, which they term liquidity-adjusted price. In real estate markets, these dimensions remain separate because liquidity varies over the economic cycle, as it is easier to sell assets in an upturn and harder in a downturn. They argue that the failure of most real estate price indices to take account of such variable liquidity is a serious weakness, since they do not provide a proper comparison of prices achieved at different points over the economic cycle. To address this weakness, Fisher el at (2003) define and develop the concept of 'constant-liquidity value' which through econometric modelling they apply to test the rigour of well-established US transaction price property indices. This showed that "the constantliquidity value index displays greater cycle amplitude and greater volatility compared to the variable-liquidity transaction price indices” Fisher el at (2003: 296). As this suggests, when 
economic downturns create thin real estate markets, even though market values may appear to have fallen, they may still overstate what property is really worth because such values cannot usually be achieved within a normal marketing period. Such insights, which point to the contingent nature of markets, also have relevance to markets where thinness is longstanding rather than temporary and is attributable to economic decline rather economic cycles.

\section{The calculative practices of valuation}

In UK real estate, the term 'valuation' is generally used to describe some form of independent estimate of the price likely to be achieved for a particular asset in land or property were it to be offered for sale (or lease) under certain assumptions, while the term 'appraisal' is generally reserved for estimates made on behalf of a particular party, taking account of their particular circumstances and project proposals. While the valuer making the estimate is not required by law to be professionally qualified, most valuations of any significance, and especially those upon which reliance is placed by lending institutions or in company accounts, are normally undertaken by those qualified as chartered surveyors, whose conduct and methods are regulated by their professional body, the Royal Institution of Chartered Surveyors (RICS). In the US, where the terms valuation and appraisal are used more interchangeably, the person referred to as a valuer in the UK is generally called as 'appraiser' (Sayce et al., 2006).

In recent decades, the RICS has begun to see itself as a global body and has reframed its professional requirements and guidance on valuation standards for an international audience. In institutional terms, the powerful regimes created by these professional standards help define what Crosby and Henneberry (2017: 188) call "the calculative practices that relate to the valuation of real property". However, such practices achieve meaning only through diffused operation, leaving significant scope for the influence of professional cultures. Indeed, they are transmitted, revised or reinforced from one generation of surveyors to another as much by custom and professional education as by regulation. Reliance on rules of thumb and the 'market devices’ identified by Weber (2016) can thus be crucial here, as shown later in the paper.

Significantly, a surveyor's opinion of value, along with their assessment of a whole raft of circumstances that may inform that value, will influence decisions taken by lenders and public funding agencies, as well as those of immediate vendors and purchasers. Often that opinion will be quoted as relevant to later valuations and transactions, thus reinforcing the connectivity of one particular expert opinion to subsequent market events. Valuers thus play a pivotal role in the way real estate markets are socially constructed, not merely by picking up, reflecting and conveying market sentiment, but in pioneering its twists and turns as they provide what many regard as expert commentary on future market prospects. In this way, professional valuers operate as one type of 'market-maker' in the sense highlighted by Smith et al. (2006: 86) since the manner in which "they perform their professionalism is itself part of the economic formatting of markets.”

Academic research on the practices of valuation has focused mainly on issues of accuracy, variation and bias (Crosby, 2000). The ability of valuers correctly to identify subsequent sale prices is the main focus of studies of valuation accuracy. Research on valuation variation has explored the extent to which two or more valuers, when asked to undertake exactly the same valuation, may produce different results. Studies of valuation bias explore the possibility that valuations may be consistently too high or low because particular forms of evidence are given too much or too little weight by valuers. As this extensive body of research demonstrates, valuation is certainly not an exact science but requires what the RICS (2012: 6) describes as 
"careful interpretation and exercise of judgement" in assessing the available evidence and other relevant information. The valuation community thus plays a pivotal role in the social construction of markets, especially as its professional networks provide the opportunity to cross-check perceptions of value and market performance with fellow experts.

Most previous studies have explored the valuation process in well-established real estate markets, such as those for investment property and housing. Indeed, apart from the work of Adair et al (2005) and the earlier study by Adams et al. (1985), there has been remarkably little research on how the calculative practices of professional valuation help construct the relatively thin real estate markets found in urban regeneration areas. Through interviewing leading market participants, including developers and financiers as well as valuers, Adair et al (2005) identified key risks and uncertainties that influence the professional valuation task in regeneration areas. They concluded that "The valuation of urban regeneration land is said to be one of the most vexed issues in the appraisal of projects due to a lack of data transparency in urban regeneration markets, shortcomings in traditional appraisal methodologies and complexities of public sector grant procedures” (Adair et al., 2005: 213).

Taking a different approach, Adams et al. (1985) grounded their work in a specific locality, looking in detail at how valuation practices affected the redevelopment prospects of some 50 sites in Manchester, UK. Crucially, they suggested that conventional valuation practices were an important reason why "Land prices in inner cities are ... revised downwards only slowly and reluctantly in response to lack of demand or excess supply", and found that this "creates a blockage in the development process and prolongs the period of vacancy" (Adams et al., 1985: 172). Both these studies pointed to the contingent nature of such valuations, but neither offered detailed evidence on exactly how professional valuers go about their task within the kind of failing market found in many regeneration areas. As a contribution towards filling this research gap in Section 4, we now turn to consider alternative valuation methods in more detail.

\section{Alternative methods of valuation}

Chartered surveyors generally recognise five main methods by which land and property can be valued (Sayce et al., 2006). These five methods respectively involve the comparison with recent sales of similar land or property; the calculation of residual development land value after projected costs and desired profits have been deducted from projected revenues in the case of land or property with development potential; the capitalisation of rental income in the case of investment property; some linkage to the profitability of the occupying business in the case of hotels, public houses and other similar uses; and for specialist properties such as power stations or chemical plants, the cost to the owner of replacing the building were that ever to become necessary. Each rely on expert judgements to construct perceptions of value, drawing on rules and conventions that have emerged among the professional community over a long period of time.

As far as development land is concerned, the valuer must choose between the comparable and residual methods, each of which we now explore in more detail. However, neither method is readily suited to regeneration areas characterised by market failure, where factors such as contamination, low demand, landowner inertia and paucity of information create "one of the most challenging tasks confronting the valuation profession today" (Adair et al, 2005: 215). 


\section{Comparable valuation}

According to the RICS (2012: 3), valuers should look for six qualities in comparable evidence of previous transactions, namely that it is

- comprehensive - ideally a number of comparables rather than a single transaction or event

- very similar - ideally identical to the item being valued

- recent - i.e. representative of the current market

- the result of an arm's length transaction in the open market

- verifiable, so far as practicable

- consistent with local market practice.”

Such requirements represent an ideal which Crosby and Henneberry (2017) argue is impossible to achieve. Indeed, the RICS (2012) acknowledges that "It is relatively rare to find two identical comparables" (p. 9). This highlights the need for valuers "to make a qualitative judgement based on experience and a broad knowledge of the local market” (p. 10). This takes valuers well beyond mere passive observation of market conditions. Expert judgements made in the face of uncertainty and partial information can take on a life of their own, and then become incorporated within broader perceptions of future market prospects. At what point, however, does the exercise of a valuer's professional judgement turn from the common sense application of broader experience to become the ingenious art of market construction in its own right? The answer must depend on how far available evidence departs from the six qualities identified above. Where evidence is reasonably robust and plentiful, even if not necessarily ideal, it will be harder for a small group of valuers, let alone a single valuer, to lead the market in particular directions. Sales or leases of similar retail units in large shopping centres probably fall into this category.

Yet, as the RICS (2008: 7) itself acknowledges, "urban sites and existing buildings with development potential, do not easily lend themselves to valuation by comparison." This is as much due to "the differences from site to site (for example in terms of development potential or construction cost)" (RICS, 2008: 7) as to the relative infrequency of such transactions in the first place. Yet, despite the fact that "the unique characteristics of urban regeneration sites made it extremely unlikely that good comparable evidence was available with the possible exception of housing sites", Adair et al. (2005: 221-222) found that "The use of comparables was the instinctive first choice of many valuers." In institutional terms, this highlights the deeplyembedded influence of professional culture in valuation practice. Nevertheless, there is very little research on exactly how valuers seek to fashion estimates of land value out of scarce comparable evidence in thin markets.

Where information is scarce or unreliable, does 'valuation in the dark' really matter, apart perhaps from providing a particular client with a figure that may not be entirely reliable? This of course depends on the knock-on effect of such calculative practices. For if doubtful comparable valuations have a broader impact in reinforcing market perceptions and framing the behaviour of other significant market actors, such as lenders and public funding agencies, they may indeed play an important role in market construction and reconstruction. Research on the commercial property investments market has demonstrated how valuations can act as an important benchmark for subsequent decision-making. Baum et al. (2000), for example, found that over half of the investment fund managers they interviewed would not sell assets below valuation, primarily because this made it problematic to secure necessary approvals from trustees and other executive bodies. In inner Manchester, Adams et al. (1985: 172) concluded that "the comparative method is felt to underpin existing values, even when no longer justified 
by the level of demand”, thus delaying or preventing downward market adjustment. It is therefore essential to know much more about the practice of comparable valuation, and exactly how it operates in such thin markets. The findings we present later in the paper seek to address this.

\section{Residual valuation}

According to the RICS (2008: 9) "a residual valuation can be expressed as a simple equation: (value of completed development) - (development costs + developer's profit) = land value". A residual valuation has the distinct advantage of tying estimates of land value to proposed or potential development projects for the land. Yet, it has one major disadvantage. Minor changes in the assumptions made on development costs and revenues, let alone developer's profits, can have a disproportionate impact on the final figure. Such variations are less important if the land is to be offered for competitive sale, for the developer able to construct the highest residual valuation will be best placed to win the competition, and that valuation necessarily becomes the best appraisal of land value. However, valuations are required for many different purposes, and where there is no competitive sale, it can be difficult to determine which residual is the most reliable. This dilemma is even more pronounced in regeneration areas where, as Adair et al. (2005) point out, risks and uncertainties are even greater as a result of potential contamination, low demand and often planning uncertainties.

Nevertheless, Adair et al. (2005) found that nine of out ten valuers they interviewed preferred to start estimating the value of urban regeneration land by means of the residual method and then cross-check the results against relevant comparable evidence. This seems a pragmatic solution, apart from one important proviso. This is that, in declining markets, residual valuations will normally produce a lower figure than comparable valuations which tend to be grounded in a relatively limited numbers of more historic transactions (Adams et al., 1985). So what happens when an owner is presented with a residual valuation that is significantly lower than what they might previously have believed the land to be worth? As might be expected owners are reluctant "to accept a nil or negative value for their land, particularly where the land has a current beneficial use as a car park or as open storage” (Adair et al., 2005: 222).

This ties in with extensive earlier work on unrealistic owner expectations of land value in thin markets (Gloster and Smith, 1989; Howes 1989; English Partnerships, 2006). The Urban Task Force (1999: 29), for example, found that "landowners often have unrealistic expectations of what their site is worth or feel unable to release sites because of the inflated values that are recorded in their accounting books”, while Syms (2010) thought it common for landowners to hold unrealistic expectations of both land value and actual prices likely to be offered by potential developers. As CPRE (2014) has argued, if landowners keep brownfield land off the market because they believe its value will increase in future, sites may remain vacant for a significant period of time. Such behaviour could be interpreted in the context of option pricing theory, which suggests that the value of development land includes the value of an option to commence construction at some optimal time in the future (Grenadier, 1995). That of course depends on whether there is any real prospect of substantial change in development circumstances in the foreseeable future, which is why option pricing theory is better attuned to analysing how landowners may react to economic cycles than to structural economic decline.

It is therefore essential to find out more about how the process of residual valuation works in practice in thin property markets, and crucially about how the results interact with owner expectations. For despite the theoretical attraction of the residual method, previous research 
suggests that it is no less problematic than the comparable method in determining regeneration land value. Understanding this better is the focus of the work reported below. However, before turning to our research method and findings, it is important to reiterate that both the comparable and residual methods are socially constructed calculative practices that have significant implications for people's perceptions of what their land is worth, and thus on their willingness to engage with regeneration strategies.

\section{RESEARCH APPROACH}

\subsection{The research location}

The research reported in this paper was designed to encourage senior and experienced surveyors to explain and reflect on how they attempted to value potential development sites (including redundant property suitable for redevelopment) in failing land markets. To avoid abstract discussion and encourage respondents to ground their evidence in specific and related examples, it was decided to focus the research on one particular failing market. This was identified by reference to the Scottish Vacant and Derelict Land Survey (SVDLS). This survey, which has been published by the Scottish Government on a continuous annual basis since 1993, with earlier initial surveys having been undertaken in 1988 and 1990, provides a valuable time series of overall trends in vacancy and dereliction in Scotland. It also informs the strategic allocation of the Scottish Government’s £9.4 million Vacant and Derelict Land Fund and helps the Government monitor the success of policies intended to reduce vacancy and dereliction. Drawing on information supplied by local authorities, SVDLS aims to record all sites of 0.1 hectares or more in Scotland that are either vacant and located within a settlement, or derelict. According to the most recent SVDLS (Scottish Government, 2019), in 2018 vacant urban land in Scotland totalled 1,992 hectares spread across 1,619 separate sites, while derelict land totalled 9,044 hectares spread across 1,929 separate sites.

The research was deliberately focused on the location with the highest concentration of vacant and derelict land of any local authority administrative area in Scotland - the City of Glasgow - in which 1,005 hectares of either vacant or derelict land was recorded on 721 separate sites in 2018 (Scottish Government, 2019). This represents the equivalent of 5.75\% of the total land area of the city. However, urban vacancy and dereliction is not spread evenly through the city, but heavily concentrated in particular parts of Glasgow, of which the area approximately two miles immediately to the north of the city centre is a prime example. This study area, which we refer to hereafter as 'North Glasgow', was selected as the focus of our discussions with senior surveyors having substantial experience in valuing development land.

North Glasgow was historically an important centre of heavy and general manufacturing, with railway engineering, iron foundries, whisky distilling and power supply, for example, previously providing large-scale employment for those living in adjacent dense tenement housing. Much of the latter was redeveloped into systems-built estates constructed by the City Council in the 1960s and 1970s, but many of these have themselves now been demolished. In recent decades, the area has suffered very significant deindustrialisation (see Figure 1), but remains home to a number of mainly low-income communities. With almost 120 hectares of vacant and derelict land within a relatively small area, people of North Glasgow experience an immediate daily sense of urban abandonment. Approximately $80 \%$ of its unused land is classified as derelict. This is generally concentrated on larger sites, and is primarily attributable 
to previous industrial contamination, with some having been temporarily grassed over. The remaining unused land is classified as vacant and is generally concentrated on smaller sites.



Figure 1: An example of the legacy of deindustrialisation in North Glasgow

Market failure within the area has been evident in the near absence, until very recently, of private development, due partly to difficult ground conditions but primarily to negative perceptions and lack of confidence in its future. Indeed, very little private-sector housing development has taken place in recent decades across the study area, apart from one site of 83 two- and three-bedroomed homes, which a national housebuilder commenced in 2017 in the north of the area with assistance available for selected purchasers from the Scottish Government’s Help to Buy (Scotland) Affordable New Build Scheme.

Major public-sector intervention is currently concentrated on two sites in the southernmost part closest to the city centre. The first of these, Sighthill, involves a £250 million redevelopment of a 1960s local authority housing estate originally built on a chemical waste dump, and is the largest of eight 'Transformational Regeneration Areas' currently underway in the city. Extensive reclamation works across the whole of Sighthill will pave the way for almost 1,000 new homes, retail and commercial development, a new school and community campus and extensive parkland, along with new bridges to better connect to the city centre and adjoining districts. The programme is led by a strategic partnership between the Scottish Government, Glasgow City Council and Glasgow Housing Association, with the latter having already built an initial 141 social homes for rent. Agreement has now been reached with a national housebuilder to build a further 198 homes for mid-market rent and 628 for sale, with that development expected to commence in mid-2019. 
Slightly further to the west, but again close to the city centre, is Port Dundas, where the redevelopment of 11 hectares of former industrial land, previously occupied by Diageo as whisky distillery, commenced in October 2018 with a target of 600 new private homes. Here, remediation works are publicly-funded to the tune of $£ 5.6$ million by the Glasgow City Region City Deal. However, the extensive areas of vacant and derelict land elsewhere in the study area, which are neither in such close proximity to the city centre, nor underpinned by substantial public-sector investment, still generate very little private-sector interest. These include a 26hectare area of vacant and derelict land at Cowlairs, previously occupied by cleared housing and recreational uses, and over 17 hectares of derelict land on the site of the now demolished Ruchill Hospital (see Figure 2). Significantly, like several other vacant and derelict sites in the vicinity, 40 of the 43 combined hectares at Cowlairs and Ruchill Hospital are listed in the most recent SVDLS as capable of short-term development. As this suggests, market failure across North Glasgow is thus evident primarily in the very substantial excess of available development land above current demand.

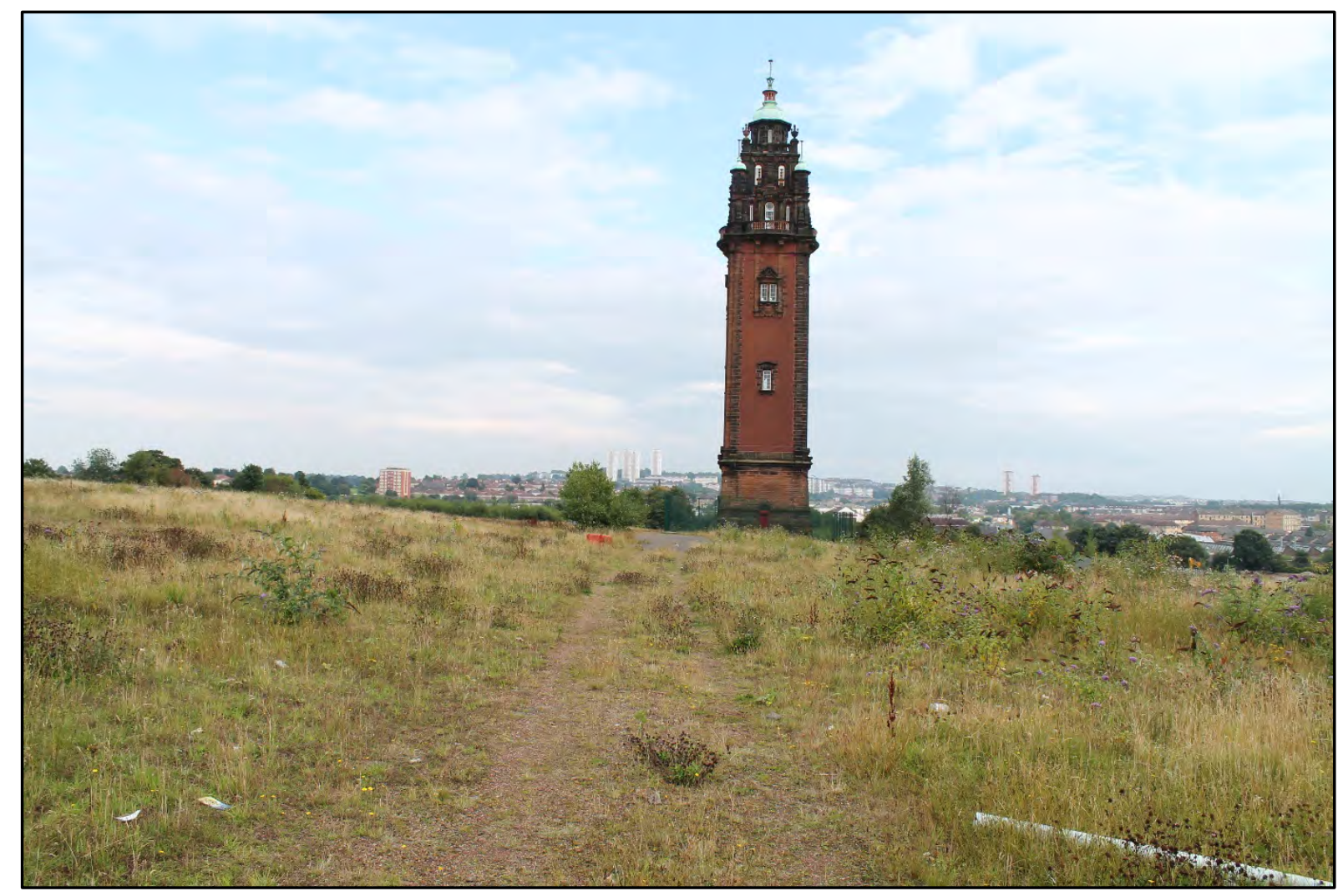

Figure 2: Derelict land at the former Ruchill Hospital, North Glasgow

\subsection{Research method}

The research itself focused on chartered surveyors based in Glasgow with known experience in the valuation of development land within the north of the city. Almost all surveyors with this particular expertise are likely to be employed by professional firms, public organisations or property development companies, rather than work on their own independently.

The basic research population was therefore drawn from the list of firms of chartered surveyors regulated by the RICS and having a Glasgow address. This produced an initial total of 103 companies. However, many of these companies specialise in building surveying, quantity 
surveying and other specialist areas and do not undertake valuation work. Others undertake particular types of valuation work, such as for residential mortgages, and have little or no expertise in valuing development land. In comparative terms, the number of RICS-regulated firms located in Glasgow reflects the city's standing as one of the UK's eight major regional property markets outside London (Cushman and Wakefield, 2018). While it is likely that the mix, expertise and working methods of Glasgow firms are broadly similar to those found in the other seven major markets (Birmingham, Bristol, Cardiff, Edinburgh, Leeds, Manchester and Newcastle), we did not collect any specific data to verify this.

By eliminating all regulated firms in Glasgow not involved in the valuation of development land, the initial population of 103 companies was reduced to 19. Two well-known Glasgow valuation firms that employ chartered surveyors but which for particular reasons are not currently registered with the RICS were added to this list, making a total of 21.

Of these 21 firms, 14 have offices across the UK (and often well beyond), and 7 operate only in Scotland, and are generally smaller. The sample was structured to reflect this diversity of firm location and size. A random sample of three UK-wide companies and two Scottish ones was selected for interview, and an approach was then made, inviting the firm to nominate a director or other senior member with expertise in the valuation of development land. On occasions when this invitation was refused, a replacement firm in the same category was selected randomly.

Three public organisations with experience in valuing development land, namely the City Council, Clyde Gateway Urban Regeneration Company and the District Valuer, were identified and approached for interview, and two of these organisations agreed to be interviewed.

The final four valuers interviewed were all chartered surveyors working for development companies in Glasgow. There is no single source from which it is possible to compile such a population, but the total number is unlikely to be large as many development companies rely on professional valuation firms for this work, rather than employ chartered surveyors in-house. It was therefore decided to approach four chartered surveyors directly who were known by the researchers to be employed by development companies in Glasgow and to have experience in valuing development land.

The main ethical issues for the research involved maintaining the anonymity of interviewees and ensuring their informed written consent. On this basis, an ethics application was submitted to, and approved by, the College of Social Sciences Research Ethics Committee at the University of Glasgow.

In summary then, of the 11 interviews, three were conducted with UK-wide professional firms, two with Scottish-based professional firms, two with public-sector organisations, and four with development companies. Where we refer in this paper to quotations from particular interviewees, we do so by reference to the order in which the interviews were undertaken, which was as follows:

Interview 1: Development company

Interview 2: Development company

Interview 3: Scottish-based professional firm

Interview 4: Scottish-based professional firm

Interview 5: Public sector 
Interview 6: UK-wide professional firm

Interview 7: Development company

Interview 8: Development company

Interview 9: UK-wide professional firm

Interview 10: UK-wide professional firm

Interview 11: Public sector

All interviewees were asked the same seven questions, which focused specifically on their likely approach to valuing vacant or derelict land in North Glasgow. The first four questions asked interviewees to choose between pre-selected answers, while the final three were openended. All eleven interviews were recorded and transcribed, producing some 54 pages of detailed interview evidence. This evidence was systematically analysed against some 43 keywords or phrases, using NVIVO software. These key words were generated from two directions. Around two-thirds repeated, or virtually repeated words used in the interview questionnaire, which had itself been derived from the analysis of previous research findings in the field. These include words such as 'comparable', 'contamination', 'expectations' and 'residual'. Roughly the other third were generated by participants themselves and these tended to include terms in common professional usage but not well covered in the academic literature, such as 'due diligence', 'no scheme world' and 'oven ready'. Analysis of the material gathered on each keyword enabled common, linked and dominant patterns of response to be identified, which were then grouped into the five themes presented in the next section. These relate to, and expand upon, the key issues raised (and often left unresolved) in the review of literature reported earlier in the paper.

\section{EMPIRICAL EVIDENCE FROM NORTH GLASGOW}

As previously mentioned, North Glasgow contains among the highest concentration of vacant and derelict land in the whole city. This section draws on the interview evidence to explore what kind of market, if any, exists in land in this area, how perceptions of market value are constructed and by whom, and what policy approaches - in the view of those interviewed might best boost local development activity. In exploring these themes in turn, the fictional nature of 'land markets' in such locations becomes apparent.

\subsection{Disinterest and inactivity as 'market' characteristics}

Almost all interviewees pointed to the lack of any real private-sector interest in buying land in North Glasgow. According to one "most of the house building industry doesn't want to go there even when local authority has put in infrastructure because the location is stigmatised" (7). Consequently, "there is very little evidence (of activity) since the recession" (5) and even "in the last 2 or 3 years there may be no transactions" (4). This produced "difficulty in working out who is in the market" (3) and lack of "clarity on market demand" (8). When pressed to specify the minimum number of potential purchasers needed to ensure some competition, one interviewee felt that "You would need to be very wary but around three parties would arguably make a market” (9). However, finding even one private-sector developer interested in site purchase was unusual since, according to another, "There are many choices for developers so why would they bother in investing in a difficult area where there is greater risk? (4)" The consequence of such lack of private-sector interest was that "Any site valuation will be restricted to a socially based scheme" (1). This meant most respondents with recent experience of valuing land in North Glasgow had acted on behalf of housing associations seeking public 
subsidy to purchase land. In other instances, valuations were commissioned by lenders assessing whether land could be used as collateral for loan applications. In both cases, there was a presumption that valuations would conform to standard RICS rules and conventions which, as discussed earlier, can be problematic to apply in failing markets.

As subsequently discussed, several of those interviewed explicitly looked to the public sector to stimulate demand. They generally preferred to work in partnership with social housing providers, acting as building contractors rather than as speculative developers in their own right. Working closely with the public sector was thus seen by private developers as essential in containing risk and securing access to vital funding from the Scottish Government, on which the viability of any project so often depended. Although an open market valuation was usually essential to any funding application, due diligence required funders to depend on the professional independence of the valuer and their compliance with normal valuation rules, rather than necessarily question the valuation itself.

Market inactivity was much reinforced by lack of site-specific information, with planning potential, utility connections and especially ground conditions all creating substantial uncertainty. Although some ground problems derived from previous foundations and made ground, land contamination was widely considered to be a "massive issue" (11), since past uses in the area had included chemical works and a soap factory, which in one case resulted in what "is basically sulphur coming up through the ground" (11). However, what most concerned interviewees was not contamination per se, but the lack of any accurate information on its nature and extent or likely remediation cost. As subsequently discussed, finding ways to cope with such missing information become an essential aspect of constructing the perception of normality.

Theoretically, this cocktail of developer disinterest and uncertain remediation costs might be expected to produce the simple answer that most land in North Glasgow had very little positive value, with some having negative value. In this context, understanding how professional valuers assess what they believe land is worth in such circumstances, to which we now turn, is crucial in explaining why the operation of land markets in practice does not necessarily reflect basic economic theory.

\subsection{Heroic attempts to compare 'like' and 'unlike'}

Professional valuers are at their most comfortable when they can find plenty of comparable evidence from similar properties that have sold recently against which to benchmark any property they are asked to value. However, all the valuers interviewed identified major problems in seeking to value land in North Glasgow by the comparable method. There were two main reasons for this.

First, as one interviewee emphasised, "If only direct comparisons were so easy. Every site is different" (1). Differences were both locational and site-specific. Locationally, "It is very seldom that two sites are comparable. There will be some differences. Different adjoining properties - very downmarket area or better quality housing” (3). While such locational differences apply to many different kinds of property (even though they may be accentuated on brownfield land), site-specific differences are particularly significant in areas such as North Glasgow. These arise from the already-mentioned uncertainties around remediation costs. "The very nature of brownfield land makes it difficult to get like for like - contamination and other technical matters makes it very difficult to say whether the sites are comparable. I am always 
very wary on comparables for that reason" (2). Interestingly, almost all of those interviewed were reluctant to get drawn into pricing 'abnormalities'. Instead, the preferred approach was to provide “a 'headline' figure but make a note reporting that there are likely abnormal costs which may be higher than the value" (5).

However, it was widely known that banks, whose lending policies are often crucial in sustaining any level of value on potential development sites, now demand greater valuation certainty following significant property losses experienced as a result of the 2008-09 recession. As one interviewee explained: "the trouble is the bank will not accept such an approach or assumptions. Banks will say we want it clarified. Therefore, the customer is expected to undertake investigation works at risk. This is unlikely to occur” (3). Yet, even when environmental consultants were commissioned "The difficulty in investigations is that one cannot cover all uncertainties. Recently, (there's been) more sophistication in site investigations. For this reason, investigations can produce results that would not have necessarily been found some five years ago. However, it isn't possible to get to an absolute figure. Some assumptions have to be made” (2). Valuers were thus torn between the banks' insistence for certainty on remediation costs and the technical and financial demands involved in meeting such requirements. Bank caution thus framed and constrained market activity by limiting participation to those with enough equity to be able to undertake detailed site investigations at their own risk and/or purchase land speculatively. Such large-scale developers are usually more interested in greenfield out-of-town locations where they perceive equity can be invested with lower risk and greater return than in places like North Glasgow.

Without much immediate comparable evidence in North Glasgow, valuers had to rely on evidence drawn more widely over space and time, deploying their 'best professional judgement' to "adjust the evidence to reflect the specific circumstances" of the site to be valued (9). Such heroic attempts to compare 'like' and 'unlike' were the second reason why comparable valuation proved highly problematic in North Glasgow. Rather than accept that valuation by comparison is an almost impossible task in such locations, interviewees tried to wrestle with whatever distant evidence they could collect in the belief that "Valuation is an art and a science which relies on judgement as well as core evidence" (9). This was no simple task since it required valuers to judge which particular figure to select out a range of potential outcomes, having first evaluated all relevant influences on value. Since such decisions could make all the difference to whether projects were funded or not, and might well be referenced in subsequent valuations, the exercise of professional judgement was central to the valuer's role as market maker.

When asked to specify the most spatially distant comparable transaction they would consider relevant and appropriate for North Glasgow, only three of the eleven interviewees drew the boundary at two miles or less. One was prepared to look for comparables up to five miles away, but the remaining seven were willing to search much further afield. One expressed a willingness to look at transactions in Edinburgh, some 40 miles away, and another would look as far as Dundee, some 80 miles away. Such behaviour might best be described as 'clutching at market straws', especially as market conditions in both of these distant cities are hardly comparable to those in North Glasgow. Emphasis was thus placed on finding comparables with similar past or intended future uses, irrespective largely of distance. One interviewee, for example, if asked to value a redundant bus garage with redevelopment potential in North Glasgow, would have no hesitation in seeking transaction evidence on former bus garages over a distance of at least five miles from the area. Others, in valuing land for social housing in North Glasgow, were quite ready to look at social housing projects in neighbouring local 
authorities, while acknowledging the need to make some adjustment if grant levels differed. Significantly, in the absence of any standard or agreed method for adjusting for such distant evidence, strong emphasis was placed on the judgement and experience of the individual valuer in determining what land might be worth in North Glasgow.

Interviewees were also asked to specify how far back they would go in time for comparable evidence. Five of the eleven specified 18 months or less as a maximum time period, while another two thought up two years would be reasonable. However, recognising the lack of any recent evidence, three interviewees were prepared to look at transactions up to three years previously, while another commented that: "In last 2 or 3 years there may be no transactions. Transactions say five years ago should be weighted depending on the circumstances at that time. Happy to go back providing I can assess the circumstances" (4). Once again, more confidence appeared to be placed in the professional ability of valuers to adjust evidence than on the robustness of the evidence itself. The more static the market, the more confident valuers seemed to be in making such adjustments, which again framed subsequent perceptions of market conditions.

It was almost impossible to reach a nil or negative value through the comparable method. In part, this was because all land was considered to have a 'scrap' value as "some people would buy sites and cap the ground ... and use it for say car wash etc" (4). Of course, in an area such as North Glasgow, demand for car washes, surface car parking and the like is strictly finite, and certainly nowhere near the extent of available land supply, so resort to some minimum scrap value for land was yet another example in which false perceptions of normality were constructed. Moreover, there were also strong cultural and institutional reasons for wanting to maintain positive land values, reflected in comments that "The Council would not welcome that the land has no value at all. The Council is of the opinion that there is always some value" (11). Yet, as this section has shown, discovering that value through the comparable method was really quite problematic. This meant that four of the valuers interviewed, working mainly but not exclusively for developers, would not use comparison at all in valuing land in North Glasgow. We therefore now turn to see if the residual method of valuation offered any better alternative.

\subsection{Reconciling residuals with owner expectations}

All interviewees, if asked to value vacant or derelict land in North Glasgow, would undertake a development appraisal, thus using the residual method of valuation. This was the sole method deployed by the four interviewees who refused to use the comparable method in such locations. The other seven, aware of the potential frailties of residual valuation, used the comparable method as a cross-check, but varied in which method they preferred if differences arose.

Residual valuation requires the valuer to take account of likely development costs and revenues. This task is easier if the valuation relates to a specific development proposal already intended to be built on the land. However, in most cases, valuers had to construct a notional proposal that depended on some perception of market normality and reflected their own view of how the site might most realistically be developed. In this case, any estimates of costs and revenues are more artificial. Crucially, this approach is "essentially an appraisal as it is not independent" (1). This is because, costs and revenues (and indeed other inputs such as the rate of interest) will vary from one developer to another. Moreover, even a single developer may change their view of costs and revenues depending on the strength or otherwise of their current business, as "If within the cycle of our construction we need to be more aggressive because we 
need the work then arguably we will slither the land margins [land value] in order to help make the investment happen. Similarly if we have lots of work then we would be less aggressive" (1). In places such as North Glasgow, relatively modest revenues coupled with uncertain (or potentially exceptional) remediation costs were likely to generate cautious residual valuations. Development prospects thus depend on whether residual values are sufficient to tempt existing owners to sell.

Here, four interviewees highlighted the unrealistic expectations of existing owners, especially those who originally acquired the land before the 2008-09 recession. According to one interviewee: "So, the challenge with historic numbers is owners' expectations. In the case of values of 2006 and 2007 the owner will have expectations beyond current reality... (This) is relevant when land owner has a historic and higher value view and they don't want to do a deal with you... Aspirations of the owner are important and their aspirations have to be managed" (1). Another said "Expectations may be clouded by historic reasons (historic book value) which don't reflect current market conditions" (5). And according to a third: "What is important is (the owner's) desire/need to sell... (There is the) issue of historic book value. It is relevant as to whether a deal can be achieved. If you value on a residual basis and can prove to the vendor that is 'what it is worth', if his expectations are higher then he will say "I don't care I'm not selling" " (3). In short, owners were often determined to cling on to their own historic perceptions of value, even where valuers produced evidence of structural market adjustment. Thus, although residuals are grounded in appraisals of likely development potential, they serve to highlight the divide between what a developer would be willing to pay for land in North Glasgow and what existing owners believe it is worth. In the context of this divide, we now turn to explore how, in the view of those interviewed, local development activity might be best stimulated.

\subsection{Tackling land market failure}

Interviewees who commented on how land market failure in North Glasgow might best be resolved, tended to look back to earlier regeneration policies that had prioritised large-scale public sector intervention and produced major physical transformations in Scotland's towns cities. One former employee of the Scottish Development Agency (which had been at the forefront of such activity in the 1980s and 1990s) explained how "we acquired from land dealers and invested in making land good, regenerating it, putting in infrastructure and then selling to developers ... creating 'oven ready' lower risk development opportunities.” He felt that even now "The way forward would be incentives / inducements either direct intervention by public authorities or tax breaks” (3). Another interviewee (7) pointed to the Crown Street regeneration project in Glasgow, a well-known exemplar from the 1990s, which was driven forward as a public-sector initiative by Glasgow Development Agency, Glasgow City Council, Scottish Homes and the New Gorbals Housing Association. A more recent organisation, the Clyde Gateway Urban Regeneration Company (which reports directly to the Scottish Government), was also singled out as a regeneration champion since it "can deal with all of the stuff including contamination, drainage, land assembly. Clyde Gateway dealt with all the difficult sites but it did require considerable funding” (5). Nevertheless, apart from the major redevelopment programmes already underway at Sighthill and Port Dundas, no plans for further such intervention in North Glasgow currently exist. A view was also expressed by two interviewees (7 and 8) that a large-scale private-sector land developer might be able to achieve a similar scale of transformation, if it could act as "a master developer enabling things to happen with a builder building houses." Ironically, however, the belief that the public sector would eventually have to rescue North Glasgow through large-scale intervention may have 
underpinned perceived land values in the area, although such a proposition would be extraordinary difficult to test.

\subsection{Challenging perceptions of normality through deliberate policy reconstruction}

In 2014, the Scottish Government's Land Reform Review Group proposed that local authorities be given powers to require that land which has been vacant or derelict for some time be sold by public auction. These proposed powers were termed 'Compulsory Sale Orders' (CSOs) (Adams, 2017). It was argued that “... there comes a point when it is no longer in the public interest for an owner to retain land and property indefinitely, without use or sale ... Public auctions arguably provide the most effective means to ascertain a fair price for vacant land and property, especially at a time of economic restructuring. They cut through the inherent difficulties involved in the valuation of such assets, which arise because actual transactions in vacant urban land are relatively few in number ... sellers are often reluctant to go to auction because the price achieved may well be lower than that which they believe to be achievable by waiting indefinitely for a purchaser. But, from a public interest perspective, this is precisely the point” (Land Reform Review Group, 2014: 123).

CSOs thus represent a deliberate attempt to reconstruct urban land markets through generating more actual land sales (and consequent transaction evidence), rather than by tackling market failure thorough large-scale public expenditure. The proposal was subsequently accepted by the Scottish Government, with legislation now awaited, although at the time of our interviews, it has received only limited initial reaction from the valuation profession. We therefore tested the response of interviewees to what was potentially a radical change to ownership rights and perceived market normality.

In response, six interviewees felt that CSOs would reduce or depress land values, although the only benchmark suggested for this view was the compensation levels payable under compulsory purchase. This is perhaps no surprise, given the inherent difficulties identified above in making any independent assessment of land value in areas experiencing market failure. It was further argued that CSOs would involve 'forced' sales that would breach the owner's property rights. Some interviewees were also concerned that only cash buyers would participate in such auctions, especially if information about planning status and ground conditions was not widely available, and if grant aid was not be available on purchases made by CSO auction. Others felt that developers might be deterred from bidding by any requirement to move ahead quickly with a scheme if successful.

Although such criticisms of radical urban land reform from well-established market actors might well have been anticipated, they do offer useful warnings of what might happen if the policy is not implemented carefully. Indeed, they are addressed in the more recent report from the Scottish Land Commission (2018) on exactly how CSOs should be implemented. Significantly, although several interviewees appeared uncomfortable with the implications, there appeared to be some agreement that the introduction of CSOs would exert downward pressure on land prices in areas of market failure. Although interviewees were not asked to consider the broader implications of CSOs, the proposed reforms are deliberately intended to stimulate development activity in such areas, even by current owners, especially if it becomes apparent any financial return can be achieved only by investment and not by keeping the land inactive over a long period of time. 


\section{CONCLUSIONS}

This paper has explored the processes by which those widely recognised to have the necessary professional expertise seek to assign some kind of value to land in 'thin' or 'fragile' markets. All the chartered surveyors interviewed for the research agreed that that no competitive market existed in land within the area to the north of the city centre where vacancy and dereliction are dominant. They struggled to find robust methods to assess land value, owing mainly to lack of transaction evidence and shortage of site-specific information. Despite this, they were still willing to place a value of land that theoretically might appear to have none. Interviewees seemed prepared to stretch their search for evidence back in time and across some considerable distance in space, believing that they could offer the necessary knowledge and expertise to apply such evidence to current market conditions in North Glasgow. Moreover, they tended to look back to places where such problems had been solved by large-scale public-sector intervention and found it difficult to relate to the radical innovation of compulsory sale that might ensure more realistic land pricing in future. The paper therefore confirms and extends earlier research on valuation in thin markets, while offering significant new evidence on the strategies deployed by valuers in seeking to maintain some perception of market normality.

As key market makers, professional valuers are clearly embedded within, and indeed help to reinforce, a culture of perceived normality that requires a value to be placed on land, whether or not any real market exists at all. Theoretically, we suggest that the norms, customs, and conventions though which this culture becomes manifest both draw their strength from the powerful underlying regime of formal professional rules and guidance, but also provide the means by which that regime is interpreted and stretched as circumstances require.

Here, a specific institutional conduit powerfully connects regimes and cultures in market making. This is the particular emphasis placed on breadth of experience and professional judgement in the process of valuation, evident not only in the written guidance from the professional body but also in the expectation of clients. Where information is missing, incomplete or incoherent, valuers are expected by lenders, housing associations and other market actors to fill in the gaps and create the perception of value even in the midst of market failure. In North Glasgow, this was reinforced by the reluctance of the City Council and of some existing landowners to accept that, in reality, much of the land there probably has a nil or negative value. In short, while valuers may appear content to script markets and market conditions through the exercise of their own professional judgement (and in a way that becomes almost self-reinforcing as those judgements are subsequently picked up and requoted by other valuers), the role of other market actors in demanding this type of performance from the valuation community should never be underestimated.

\section{REFERENCES}

ADAIR, A., HUTCHISON, N., BURGESS, J. and ROULAC, S. (2005) 'The appraisal of urban regeneration land', Journal of Property Investment and Finance, 23, 213-233.

ADAMS, D. (2017) 'Tackling hardcore vacancy through compulsory sale orders', in Henneberry, J. (ed) Transience and Permanence in Urban Development, Chichester, WileyBlackwell, pp. 215-229. 
ADAMS, D. and TIESDELL, S. (2010) 'Rethinking state-market relations in land and property development', Planning Theory and Practice, 11, 187-207.

ADAMS, D., BAUM, A. and Macgregor, B. (1985) 'The influence of valuation practices upon the price of vacant inner city land’, Land Development Studies, 2, 157-173.

BAUM, A., CROSBY, N., GALLIMORE, P. MCALLISTER, P. and GRAY, A. (2000) The Influence of Valuers and Valuations on the Workings of the Commercial Property Investment Market, Paper given at RICS Cutting Edge Conference, London.

CPRE (2014) Removing Obstacles to Brownfield Development, London, Campaign to Protect Rural England.

CROSBY, N. (2000) 'Valuation accuracy, variation and bias in the context of standards and expectations’, Journal of Property Investment and Finance, 18, 130-161.

CROSBY, N. and HENNEBERRY, J. (2017) 'Valuation and evolution of new uses and buildings', in Henneberry, J. (ed) Transience and Permanence in Urban Development, Chichester, Wiley-Blackwell, pp. 185-198.

CROSBY, N., LIZIERI, C., MCALLISTER, P. and MARTIN, S (2009) Issues in Property Investment Valuation: A Discussion Paper for the Investment Property Forum, IPF Research Programme Short Papers Series, Paper 3, London, Investment Property Forum.

CUSHMAN and WAKEFIELD (2018) UK Marketbeat 2018 Q1, London, Cushman and Wakefield.

ENGLISH PARTNERSHIPS (2006) The Brownfield Guide: A Practitioner's Guide to Land Reuse in England, London, English Partnerships.

FISHER, J. D., GATZLAFF, D., GELTNER, D. and HAURIN, D. (2003) 'Controlling for the impact of variable liquidity in commercial real estate price indices', Real Estate Economics, 31, 269-303.

GLOSTER, M. and SMITH, N. (1989) Inner Cities - A Shortage of Sites, London, RICS.

GRENADIER, S. (1995) 'The persistence of real estate cycles', Journal of Real Estate Finance and Economics, 10, 95-119.

HEALEY, P. (1991) 'Urban regeneration and the development industry’, Regional Studies, 25, 97-110.

HENNEBERRY, J. and ROBERTS, C. (2008) 'Calculated Inequality? Portfolio Benchmarking and Regional Office Property Investment in the UK', Urban Studies, 45, 12171241.

HOWES, C. (1989) 'Special Report Land Assembly: Private Sector gets a Boost', Chartered Surveyor Weekly, 19 January 1989, 61-63. 
JEPPERSON R. L. (1991) 'Institutions, institutional effects and institutionalism', in Powell, W. W. and DiMaggio, P. J. (eds) The New Institutionalism in Organization Analysis, Chicago, University of Chicago Press, pp. 143-163.

LAND REFORM REVIEW GROUP (2014) The Land of Scotland and the Common Good, Scottish Government, Edinburgh.

MILLER, P. (1994) 'Accounting as a social and institutional practice: An introduction', in Hopkins, A. G. and Miller P. (eds) Accounting as Social and Institutional Practice, Cambridge, Cambridge University Press, pp 1-39.

MILLER, P. (2001) 'Governing by numbers: why calculative practices matter', Social Research, 68, 377-396.

OXLEY, M (2004) Economics, Planning and Housing, Basingstoke, Palgrave.

RICS (2008) Valuation of Development Land, Valuation Information Paper 12, London, Royal Institution of Chartered Surveyors.

RICS (2012) Comparable Evidence in Property Valuation, London, Royal Institution of Chartered Surveyors.

SAYCE, S., SMITH, J., COOPER, R. and VENMORE-ROWLAND, P. (2006) Real Estate Appraisal: From Value to Worth, Oxford, Blackwell Publishing.

SCOTTISH GOVERNMENT (2019) Scottish Vacant and Derelict Land Survey 2018, Edinburgh, Scottish Government.

SCOTTISH LAND COMMISSION (2018) Compulsory Sale Orders, Inverness, Scottish Land Commission.

SMITH, S. J., MUNRO, M. and CHRISTIE, H. (2006) 'Performing (housing) markets', Urban Studies, 43, 81-98.

SYMS, P. (2010, 2nd edn) Land, Development and Design, Oxford, Wiley-Blackwell.

URBAN TASK FORCE (1999) Towards an Urban Renaissance, London, E and F N Spon.

WEBER, R. (2016) 'Performing property cycles’, Journal of Cultural Economy, 9, 587-603. 